\title{
Perancangan Produk Boneka Pada Unit Usaha Kecil Untuk Meningkatkan Kemandirian Dengan Metode LP - Simpleks
}

\author{
Miftahul Imtihan \\ Program Studi Teknik Industri \\ Sekolah Tinggi Teknologi Muhammadiyah Cileungsi \\ miftahul_imtihan@yahoo.com
}

\begin{abstract}
ABSTRAK
Usaha Kecil merupakan bentuk usaha dengan modal dan tingkat kesulitan dalam membangun usahanya tidak sesulit usaha menengah maupun usaha dengan skala besar. Adapun Usaha kecil yang dimaksud adalah proses produksi kerajinan boneka. Usaha kerajinan boneka tersebut dilakukan oleh para pelaku usaha kecil dimulai dari proses pemilihan bahan baku boneka, model boneka yang diproduksi, proses penjahitan dan finishing boneka, serta model penjualan boneka ke tangan konsumen langsung. Permasalahan yang dihadapi oleh pelaku usaha kecil kerajinan boneka adalah sumber dana yang sangat terbatas untuk melakukan perputaran usaha, tenaga kerja yang bersifat harian lepas dan sangat minim, persaingan harga jual boneka ke tangan konsumen, serta penerapan model produksi yang relatif konvensional. Adapun tujuan yang ingin dicapai dalam penelitian ini adalah agar mampu merancang produksi boneka secara optimal sehingga pelaku usaha kecil mampu meningkatkan kapasitas produksi dan mampu meningkatkan kemandirian melalui pendekatan model LP-Simpleks. Hasil penelitian dengan metode LP-Simplek menunjukkan bahwa kombinasi produksi pada tiga varian terdiri atas Produksi Bantal Leher (X) adalah 28 buah, produksi Bantal Sandaran Mobil (Y) adalah 28 buah, serta Produksi Bantal Bulat (Z) adalah 13 buah. Dengan kombinasi tersebut akan mampu memperoleh profit kurang lebih Rp. 204.607.200,00 dalam setiap bulannya. Artinya dengan menerapkan model LP-Simpleks pelaku usaha kecil memproduksi berdasarkan jumlah produk dengan memperhatikan total biaya dengan hasil yang optimal pada masing-masing variannya, sehingga ketika model ini dikembangkan maka akan mampu meningkatkan kemandirian ekonomi yang berdaulat bagi pelaku usaha kecil, tenaga kerja, dan akan mampu menopang perekonomian masing-masing elemen yang menghasilkan kemandirian ekonomi yang berdaya saing.
\end{abstract}

Kata Kunci : Perancangan Produk, LP-Simpleks, Kemandirian

\section{PENDAHULUAN}

Usaha Kecil merupakan bentuk usaha dengan modal dan tingkat kesulitan dalam membangun usahanya tidak sesulit usaha menengah maupun usaha dengan skala besar. Usaha kecil yang dimaksud adalah proses pembuatan dan pengolahan kerajinan boneka. Usaha kerajinan boneka tersebut dilakukan oleh para pelaku usaha kecil dimulai dari proses pemilihan bahan baku boneka, model boneka yang diproduksi, proses penjahitan dan finishing boneka, serta model penjualan boneka ke tangan konsumen langsung.

Banyaknya persoalan yang dihadapi pengusaha kerajinan boneka harus disikapi secara tepat dan proporsional yang mengacu kepada keterbatasan maupun kelebihan yang dimilikinya. Disi lain, persaingan yang sangat ketat diantara produsen kerajinan boneka, maka juga diperlukan usaha yang keras agar keberlanjutan usaha tersebut bisa berjalan dengan harapan. Upaya yang terus dalam mempertahankan usaha dengan produksi boneka perlu adanya pendampingan dari berbagai terutama pihak yang mau berinvestasi (pemodal), pihak akademik ataupun pihak lain yang dapat menumbuhkembangkan proses usaha tersebut. Pada perancangan produk kerajinan boneka perlu dicermati kembali bahkan jika memungkinkan harus dilakukan improving continuous melalui inovasi produk dan kreatifitas [2], terutama dalam merancang produk yang elegant, sehingga produk yang dihasilkan mampu memenuhi kebutuhan pelanggan secara berkelanjutan serta terdapatnya optimalisasi perancangan produk boneka yang mampu dihandalkan. Adanya pemenuhan kebutuhan pelanggan dan 
kualitas produksi boneka yang berjalan secara bersama diharapkan mampu meningkatkan kemandirian ekonomi produsen maupun pekerja sehingga dapat menopang ekonomi masing-masing keluarga.

Jika pengusaha maupun pekerja mempunyai penghasilan yang tercukupi dan terpenuhi sistem usahanya serta kebutuhan perekonomian dalam kehidupan nyata, maka kemandirian ekonomi dapat dipertahankan baik untuk jangka menengah maupun jangka panjang. Hal ini lebih dikarenakan bahwa kemandirian ekonomi yang layak akan mampu menjaga stabilitas pangan bagi masyarakat dan pelaku ekonomi secara global.

Fluktuasi permintaan barang yang tidak menentu dari satu periode ke periode lain menyebabkan kekurangan atau kelebihan produksi. Masalah-masalah lainnya adalah bahan baku, jam kerja mesin, jam kerja tenaga kerja, dan permintaan-permintaan akan produk-produk yang dihasilkan. Analisis menggunakan Metode Simpleks yang merupakan Linear Programming bertujuan untuk memaksimalkan laba berupa fungsi liniear [3].

\section{1) Perancangan Produk Boneka.}

Boneka (dari bahasa Portugis boneca) adalah sejenis mainan yang bermacam-macam bentuknya, terutamanya manusia atau hewan, serta tokoh-tokoh fiksi. Secara umum bentuk boneka bervariasi dan memberikan kontribusi dalam memberikan permainan pada anak-anak, dalam dunia film boneka menjadi aktor untuk memperankan dalam suatu cerita.

Usaha Kecil dan Menengah dalam pembuatan boneka cukup diperhitungkan dalam program kreatifitas masyarakat, kegiatan ini membutuhkan tenaga kerja yang banyak dan bisa memperdayakan pemuda pemudi untuk membuatnya dan boneka ini paling diminati oleh semua kalangan terutama wanita dan anak-anak.

Untuk sukses dalam bisnis ini, kreatifitas dalam menciptakan kreasi boneka yang unik dan mengikuti zaman dengan harga yang bersaing adalah kunci utamanya. Untuk memproduksi boneka diperlukan beberapa tahapan yaitu proses penentuan bentuk boneka, pembuatan pola, penjahitan bahan, dan pengisian bahan atau isi dalam boneka, dan terakhir penambahan asesoris agar lebih menarik. Menurut UU No. 20 Tahun 2008[4], UKM terbagi menjadi dua kategori yaitu:

Usaha kecil merupakan entitas yang memiliki kriteria berikut ini:

a) Memiliki jumlah kekayaan lebih dari Rp 50.000.000 sampai dengan Rp 500.000.000 yang tidak termasuk dengan tanah dan juga bangunan tempat usaha.

b) Memiliki hasil dari penjualan sebanyak $\mathrm{Rp} 300.000 .000$ salam setahun sampai dengan $\mathrm{Rp}$ 2.500.000.000.

Sedangkan untuk Usaha Menengah adalah suatu entitas yang berkriteria berikut ini :

a) Memiliki jumlah kekayaan Rp 500.000.000 dengan paling banyak Rp 10.000.000.000 yang tidak termasuk dengan tanah dan bangungan sebagai tempat usahanya.

b) Memiliki hasil penjualan yang bernilai lebih dari Rp 2.500.000.000 pertahun sampai dengan Rp 50.000.000.000 paling banyak.

\section{2) Kemandirian}

Kesejahteraan masyarakat dalam melaksanakan usaha, perlu pendampingan oleh profesional usaha, dari kalangan perguruan tinggi, motivator, pakar ekonomi, pakar pemasaran maupun dari instansi pemerintah, agar dapat mandiri dalam menjalankan usaha dan meningkatkan perekomonian keluarga, meskipun sebagian dari kebutuhan-kebutuhan ekonomi untuk biaya yang lebih minim atau dengan tujuan lain lebih memilih impor dari luar negeri

Beberapa hal yang perlu dilakukan oleh masyarakat terkait kemandirian sebagai warga negara adalah usaha dalam bentuk perekonomian secara mikro di wilayah tertentu dan khususnya masing-masing anggota keluarga mempunyai kemampuan untuk menggali sumber daya yang berada dilingkungan untuk ditumbuhkembangkan secara terintegrasi antara produsen, konsumen serta sumber bahan baku sebagai material produksi yang akan di proses menjadi barang atau produk yang mempunyai nilai tambah. Walaupun terkadang banyak keterbatasan sumber daya baik SDM maupun Material ataupun Finansial dan Peralatan produksi [5]. 


\section{3) LP-Simpleks}

Untuk menentukan pengalokasian keterbatasan persoalan diantara beberapa aktifitas dalam persaingan di dunia usaha metode yang dipergunakan adalah metode simpleks. Adapun langkah yang harus dijalankan terlebih dahulu adalah mengubah suatu bentuk LP menjadi Bentuk Standar Metode Simpleks [6], caranya adalah sebagai berikut :

a. Semua batasan adalah persamaan (dengan sisi kanan yang Non Negatif)

b. Semua variabel keputusan adalah Non Negatif

c. Fungsi tujuan berupa Maksimasi dan Minimasi

Adapun bentuk standarnya adalah:

$$
\text { Maksimum atau Minimun } Z=\sum_{j=1}^{n} C j X j
$$

Batasan:

$$
\begin{gathered}
\sum_{j=1}^{n} a_{i j} x_{j}=b i \quad \text { untuk } i=1,2, \ldots n \\
x_{j} \geq 0 \quad \text { untuk } j=1,2, \ldots n
\end{gathered}
$$

Karena semua batasan atau kendala harus berbentuk persamaan, maka jika ada kendala yang berbentuk pertidaksamaan harus dikonversikan menjadi persamaan dengan memasukkan Variabel Slack atau Surplus. Sebuah batasan yang bertanda $\leq$ atau $\geq$ dapat dikonversikan menjadi $=$ dengan mengurangkan Variabel Surplus (Menambahkan Variabel Slack) terhadap sisi kiri batasan tersebut.sebuah batasan dengan sisi kanan yang berharga Negatif dapat diubah menjadi Positif dengan mengalikan Negatif Satu.

Langkah-langkah penyelesaian Metode LP-Simpleks:

a. Buat Model Formulasi dan Standarisasi

\begin{tabular}{|c|c|c|c|c|c|c|c|c|c|c|}
\hline \multirow{3}{*}{$\begin{array}{c}\text { Variabel } \\
\text { Dasar }\end{array}$} & \multirow{3}{*}{ Tujuan } & $\mathrm{Cj}$ & $\mathrm{C}_{1}$ & $\mathrm{C}_{2}$ & $\ldots$ & $\mathrm{Cn}$ & 0 & 0 & $\ldots$ & 0 \\
\hline & & $\mathrm{k}$ & \multirow{2}{*}{$X_{1}$} & \multirow{2}{*}{$\mathrm{X}_{2}$} & \multirow{2}{*}{$\ldots$} & \multirow{2}{*}{$\mathrm{Xn}$} & \multirow{2}{*}{$\mathrm{S}_{1}$} & \multirow{2}{*}{$\mathrm{S}_{2}$} & \multirow{2}{*}{$\ldots$} & \multirow{2}{*}{$\mathrm{Sn}$} \\
\hline & & $q$ & & & & & & & & \\
\hline $\mathrm{S}_{1}$ & 0 & $b_{1}$ & $\mathrm{a}_{11}$ & $\mathrm{a}_{11}$ & $\ldots$ & $a_{1 n}$ & 1 & 0 & $\ldots$ & 0 \\
\hline $\mathrm{S}_{2}$ & 0 & $b_{2}$ & $a_{21}$ & $a_{22}$ & $\ldots$ & $a_{2 n}$ & 0 & 1 & $\ldots$ & 0 \\
\hline$\ldots$ & $\cdots$ & $\cdots$ & $\ldots$ & $\ldots$ & $\ldots$ & $\ldots$ & $\cdots$ & $\cdots$ & $\ldots$ & $\ldots$ \\
\hline$\ldots$ & $\ldots$ & $\ldots$ & $\ldots$ & $\ldots$ & $\ldots$ & $\ldots$ & $\ldots$ & $\ldots$ & $\ldots$ & $\ldots$ \\
\hline \multirow{3}{*}{$\mathrm{S}_{\mathrm{m}}$} & 0 & $b_{m}$ & $a_{m 1}$ & $a_{\mathrm{m} 2}$ & $\ldots$ & $\mathrm{a}_{\mathrm{mn}}$ & 0 & 0 & $\ldots$ & 1 \\
\hline & $\mathrm{Zj}$ & 0 & 0 & 0 & $\ldots$ & 0 & 0 & 0 & $\ldots$ & 0 \\
\hline & & $\mathrm{Cj}-\mathrm{Zj}$ & $\mathrm{C}_{1}$ & $\mathrm{C}_{2}$ & $\ldots$ & $\mathrm{Cn}$ & 0 & 0 & $\ldots$ & 0 \\
\hline
\end{tabular}

b. Bentuk tabel awal Simpleks

Tabel 1. LP - Simpleks [7]:

c. Tentukan KOLOM KUNCI diantara kolom variabel yang mengandung Nilai Cj-Zj Paling POSITIF untuk kasus MAKSIMASI dan atau mengandung Nilai $\mathrm{Cj}-\mathrm{Zj}$ Paling NEGATIF untuk kasus MINIMASI.

d. Tentukan BARIS KUNCI diantara baris variabel yang memiliki RASIO KUANTITAS dengan NILAI POSITIF terkecil.

$$
\text { Rasio Kuantitas } k e-i=\frac{b_{i}}{\text { unsur kolom kunci yang positif }}
$$

Bentuk tabel berikutnya dengan memasukkan Variabel Pendatang ke KOLOM Variabel Dasar dan mengeluarkan Variabel Perantau dari KOLOM tersebut serta lakukan transformasi Baris-baris Variabel.

e. Lakukan Uji OPTIMALISASI

Dengan kriteria jika semua koefisien pada baris $\mathrm{Cj}-\mathrm{Zj}$ sudah tidak ada lagi yang bernilai POSITIF (Untuk MAKSIMASI), dan sudah tidak ada lagi yang bernilai NEGATIF (Untuk MINIMASI) berarti Tabel sudah OPTIMAL. 


\section{METODOLOGI PENELITIAN}

Beberapa metode pengumpulan data terkait penelitian pada usaha kecil Produk Boneka ini yaitu sebagai berikut:

1. Metode Literatur: Yaitu mengambil data yang berkaitan dengan permasalahan dalam penelitian melalui buku-buku literatur (kepustakaan), materi di internet, jurnal-jurnal penelitian, prociding dan lain-lain agar data tersebut mempunyai dasar teori yang memadai.

2. Metode Observasi: Yaitu proses mengambil data produk boneka dengan cara berkunjung langsung atau survei ke lokasi penelitian dengan mengamati dari awal proses pemilihan material boneka sampai barang jadi berbentuk produk boneka.

3. Metode Interview:Yaitu proses mencari data melalui interview atau wawancara langsung kepada pihak terkait pada usaha kecil produk boneka terutama dengan pelaku usaha kecil di bidang boneka.

4. Populasi Dan Sampel Penelitian: Populasi dalam penelitian ini adalah seluruh data Produksi Boneka dengan semua varian produksi. Untuk memudahkan proses penelitian maka digunakan sampel yang representatif dikarenakan terbatasnya waktu penelitian dan kesempatan yang diberikan oleh unit usaha kecil. Adapun untuk Sampel yang dimaksud yaitu diambil dengan cara mengambil dan menetapkan produk boneka dengan tingkat order yang tinggi (Bantal Leher, Bantal Sandaran Mobil, Bantal Bulat).

5. Analisa Data dan Rancangan Penelitian: Data-data hasil penelitian yang terkumpul akan dilakukan pegolahan data dengan menggunakan Metode LP-Simpleks, sedangkan untuk menganalisa data hasil penelitiannya menggunakan analisa kuantitatif dan deskriptif kualitatif.

\section{HASIL DAN PEMBAHASAN}

\section{1) Hasil Penelitian}

Hasil penelitian yang diperoleh pada unit usaha kecil produksi boneka terdiri atas beberapa data-data yang akan diolah dengan metode LP-Simplek. Data-data yang dimaksud adalah sebagai berikut:

1. Variabel Keputusan terkait proses pembuatan boneka usaha kecil yaitu :

$$
\begin{aligned}
& X=\text { Bantal Leher Per-hari } \\
& Y=\text { Bantal Sandaran Mobil Per-hari } \\
& Z=\text { Bantal Bulet Per-hari }
\end{aligned}
$$

2. A. Fungsi Pendapatan berdasarkan varian produk boneka:

Tabel 2. Pendapatan (Dalam satuan hari)

\begin{tabular}{|l|c|c|c|c|}
\hline \multicolumn{1}{|c|}{ PENDAPATAN } & $\begin{array}{c}\text { JAM } \\
\text { KERJA } \\
\text { Per-hari }\end{array}$ & $\begin{array}{c}\text { PRODUKSI } \\
\text { Per-hari }\end{array}$ & $\begin{array}{c}\text { HARGA } \\
\text { JUAL } \\
\text { Per-hari }\end{array}$ & $\begin{array}{c}\text { PENDAPATAN } \\
\text { Per-hari }\end{array}$ \\
\hline $\mathrm{X}=$ Bantal Leher & 8 & 35 & 14.000 & 3.920 .000 \\
\hline $\mathrm{Y}$ = Bantal Sandaran Mobil & 8 & 39 & 17.000 & 5.304 .000 \\
\hline $\mathrm{Z}=$ Bantal Bulet & 8 & 42 & 11.000 & 3.696 .000 \\
\hline
\end{tabular}

B. Biaya Material Boneka Berdasarkan Varian Produksi

Tabel 3. Varian Produksi

\begin{tabular}{|l|c|c|c|}
\hline \multicolumn{1}{|c|}{ MATERIAL } & $\begin{array}{c}\text { PRODUKSI } \\
\text { Per-hari }\end{array}$ & $\begin{array}{c}\text { HARGA } \\
\text { MATERIAL }\end{array}$ & $\begin{array}{c}\text { BIAYA MATERIAL } \\
\text { Per-hari }\end{array}$ \\
\hline $\mathrm{X}=$ Bantal Leher & 35 & 3.750 & 1.050 .000 \\
\hline $\mathrm{Y}=$ Bantal Sandaran Mobil & 39 & 3.675 & 1.146 .600 \\
\hline $\mathrm{Z}=$ Bantal Bulet & 42 & 3.350 & 1.125 .600 \\
\hline
\end{tabular}


C. Biaya Upah Tenaga Kerja

Tabel 4. Upah Tenaga Kerja

\begin{tabular}{|l|c|c|c|}
\hline \multicolumn{1}{|c|}{ MATERIAL } & $\begin{array}{c}\text { PRODUKSI } \\
\text { Per-hari }\end{array}$ & $\begin{array}{c}\text { HARGA } \\
\text { MATERIAL }\end{array}$ & $\begin{array}{c}\text { BIAYA } \\
\text { MATERIAL } \\
\text { Per-hari }\end{array}$ \\
\hline $\mathrm{X}=$ Bantal Leher & 35 & 1.350 & 378.000 \\
\hline $\mathrm{Y}=$ Bantal Sandaran Mobil & 39 & 1.250 & 390.000 \\
\hline $\mathrm{Z}=$ Bantal Bulet & 42 & 1.100 & 369.600 \\
\hline
\end{tabular}

(Sumber : Data diolah)

D. Kelompok Pekerjaan (Dalam satuan waktu @jam):

Tabel 5. Pekerjaan Dalam Satuan Waktu

\begin{tabular}{|l|c|c|c|}
\hline \multicolumn{1}{|c|}{$\begin{array}{c}\text { KELOMPOK } \\
\text { PEKERJAAN }\end{array}$} & $\begin{array}{c}\text { Bagian } \\
\text { Mal-Pola }\end{array}$ & $\begin{array}{c}\text { Bagian } \\
\text { Sewing-Jahit }\end{array}$ & Isian - Assesoris \\
\hline $\mathrm{X}=$ Bantal Leher & 3 & 2 & 1 \\
\hline $\mathrm{Y}=$ Bantal Sandaran Mobil & 2 & 2 & 1 \\
\hline $\mathrm{Z}=$ Bantal Bulet & 2 & 1 & 2 \\
\hline Jam Kerja Tersedia & 104 & 56 & 48 \\
\hline
\end{tabular}

3. Fungsi Batasannya adalah :

$$
\begin{aligned}
3 X+2 Y+2 Z & \leq 104 \\
2 X+2 Y+Z & \leq 56 \\
X+Y+2 Z & \leq 48
\end{aligned}
$$

Batas Tanda ; X, Y, Z $>0$

4. Formula LP - Simpleks adalah:

Maksimum $\mathrm{Z}=2.492 .000 \mathrm{X}+3.767 .400 \mathrm{Y}+2.200 .800 \mathrm{Z}$

Fungsi Pembatas :

$$
\begin{gathered}
3 X+2 Y+2 Z \leq 104 \\
2 X+2 Y+Z \leq 56 \\
X+Y+2 Z \leq 48
\end{gathered}
$$

Dengan Batas Tanda ; X, Y, Z >0

Metode Simpleks merupakan solusi pemecahan masalah ketika menggunakan persamaan lebih dari dua variabel. Untuk unit usaha kecil dengan produksi boneka dilakukan dengan mengambil beberapa data yang terkait dengan tiga variabel pengukuran dalam proses pembuatan boneka, adapun varian produk boneka yang akan dibahas dalam penelitian ini adalah (1) Bantal Leher, (2) Bantal Sandaran Mobil, (3) Bantal Bulet. Estimasi pendapatan (profit) usaha kecil produk boneka dihitung dengan pertimbangan operasional diantaranya; (a) biaya operasional untuk material boneka yang sudah terpilih, dan (b) biaya upah tenaga kerja.

Adapun untuk batas-batas kendala dalam proses produksi dimasukkan dalam fungsi pertidaksamaan secara matematis sebagaimana terlihat pada data di atas. Berikut pemecahan dengan metode LP - Simpleks:

$$
\begin{array}{lll}
\text { MAX. Z } & =2,492,000 \mathrm{X}+3,767,400 \mathrm{Y}+2,200,800 \mathrm{Z}+0 \mathrm{~S} 1+0 \mathrm{~S} 2+0 \mathrm{~S} 3 \\
\text { Batasan-batasan } & =3 \mathrm{X}+2 \mathrm{Y}+2 \mathrm{Z}+1 \mathrm{~S} 1+0 \mathrm{~S} 2+0 \mathrm{~S} 3=104 \\
& =2 \mathrm{X}+2 \mathrm{Y}+1 \mathrm{Z}+0 \mathrm{~S} 1+1 \mathrm{~S} 2+0 \mathrm{~S} 3=56 \\
& =\mathrm{X}+\mathrm{Y}+2 \mathrm{Z}+0 \mathrm{~S} 1+0 \mathrm{~S} 2+1 \mathrm{~S} 3=48 \\
\text { Batas Tanda } & =\mathrm{X}, \mathrm{Y}, \mathrm{Z}, \mathrm{S} 1, \mathrm{~S} 2, \mathrm{~S} 3 \geq 0
\end{array}
$$


Tabel 6. Simpleks untuk Kolom Kunci:

\begin{tabular}{|c|c|c|c|c|c|c|c|c|c|}
\hline \multirow{2}{*}{$\begin{array}{l}\text { VARIABEL } \\
\text { DASAR }\end{array}$} & \multirow{2}{*}{ TUJUAN } & \multicolumn{2}{|c|}{$\mathbf{C j}$} & \multirow{2}{*}{$\frac{2,492.00}{\mathbf{X}}$} & \multirow{2}{*}{$\frac{3,767.40}{\mathbf{Y}}$} & \multirow{2}{*}{$\frac{2,200.80}{\mathbf{Z}}$} & \multirow{2}{*}{$\begin{array}{c}0 \\
\text { S1 }\end{array}$} & \multirow{2}{*}{$\begin{array}{c}0 \\
\mathbf{S 2}\end{array}$} & \multirow{2}{*}{$\begin{array}{c}0 \\
\mathbf{S 3}\end{array}$} \\
\hline & & $\mathbf{K}$ & $\mathbf{Q}$ & & & & & & \\
\hline S1 & 0 & \multicolumn{2}{|c|}{104} & 3 & 2 & 2 & 1 & 0 & 0 \\
\hline S2 & 0 & \multicolumn{2}{|c|}{56} & 2 & 2 & 1 & 0 & 1 & 0 \\
\hline S3 & 0 & \multicolumn{2}{|c|}{48} & 1 & 1 & 2 & 0 & 0 & 1 \\
\hline \multicolumn{2}{|c|}{$\mathbf{Z j}$} & \multicolumn{2}{|c|}{0} & 0 & 0 & 0 & 0 & 0 & 0 \\
\hline \multicolumn{4}{|c|}{$\mathbf{C j}-\mathbf{Z} \mathbf{j}$} & 2492.00 & 3767.40 & 2200.80 & 0 & 0 & 0 \\
\hline
\end{tabular}

Tabel 7. Baris Kunci:

\begin{tabular}{|c|c|c|c|c|c|c|c|c|c|}
\hline \multirow{2}{*}{$\begin{array}{l}\text { VARIABEL } \\
\text { DASAR }\end{array}$} & \multirow{2}{*}{ TUJUAN } & $\mathbf{C j}$ & $2,492.00$ & $3,767.40$ & $2,200.80$ & 0 & 0 & 0 & \multirow{2}{*}{ RASIO } \\
\hline & & $\mathbf{K}$ & $\mathbf{X}$ & $\mathbf{Y}$ & $\mathbf{Z}$ & S1 & S2 & S3 & \\
\hline $\mathrm{S} 1$ & 0 & 104 & 3 & 2 & 2 & 1 & 0 & 0 & 52 \\
\hline S2 & 0 & 56 & 2 & 2 & 1 & 0 & 1 & 0 & 28 \\
\hline $\mathrm{S} 3$ & 0 & 48 & 1 & 1 & 2 & 0 & 0 & 1 & 48 \\
\hline \multicolumn{2}{|c|}{$\mathbf{Z} \mathbf{j}$} & 0 & 0 & 0 & 0 & 0 & 0 & 0 & \\
\hline \multicolumn{3}{|c|}{$\mathbf{C} \mathbf{j}-\mathbf{Z} \mathbf{j}$} & 2492.00 & 3767.40 & 2200.80 & 0 & 0 & 0 & \\
\hline
\end{tabular}

Tabel 8. Iterasi Pertama:

\begin{tabular}{|c|c|c|c|c|c|c|c|c|c|c|}
\hline \multirow{2}{*}{$\begin{array}{c}\text { VARIABEL } \\
\text { DASAR }\end{array}$} & \multirow{2}{*}{ TUJUAN } & \multicolumn{2}{|c|}{$\mathbf{C j}$} & \multirow{2}{*}{$\frac{2,492.00}{\mathbf{X}}$} & \multirow{2}{*}{$\begin{array}{c}3,767.40 \\
\mathbf{Y}\end{array}$} & \multirow{2}{*}{$\begin{array}{c}2,200.80 \\
\mathbf{Z} \\
\end{array}$} & \multirow{2}{*}{$\begin{array}{c}0 \\
\mathbf{S 1} \\
\end{array}$} & \multirow{2}{*}{$\begin{array}{c}0 \\
\mathbf{S 2} \\
\end{array}$} & \multirow{2}{*}{$\begin{array}{c}0 \\
\mathbf{S 3} \\
\end{array}$} & \multirow{2}{*}{ RASIC } \\
\hline & & $\mathbf{K}$ & $\mathbf{Q}$ & & & & & & & \\
\hline $\mathrm{S} 1$ & 0 & \multicolumn{2}{|c|}{104} & 3 & 2 & 2 & 1 & 0 & 0 & 52 \\
\hline $\mathbf{Y}$ & 3767.40 & \multicolumn{2}{|c|}{28} & 1 & 1 & 0.5 & 0 & 0.5 & 0 & 56 \\
\hline S3 & 0 & \multicolumn{2}{|c|}{48} & 1 & 1 & 2 & 0 & 0 & 1 & 24 \\
\hline \multicolumn{2}{|c|}{$\mathbf{Z j}$} & \multicolumn{2}{|c|}{105487.20} & 3767.40 & 3767.40 & 1883.70 & 0 & 1883.70 & 0.00 & \\
\hline \multicolumn{4}{|c|}{$\mathbf{C} \mathbf{j}-\mathbf{Z j}$} & -1275.40 & 0.00 & 317.10 & 0 & -1883.70 & 0 & \\
\hline
\end{tabular}

D. BARIS BARU selain BARIS KUNCI BARIS LAMA - (RASIO KUNCI x BARIS KUNCI LAMA)

$=[8]$

$\mathrm{RK}=1 / 2$

\begin{tabular}{|c|c|c|c|c|c|c|c|c|}
\hline S3 & 0 & 48 & 1 & 1 & 2 & 0 & 0 & $\mathbf{1}$ \\
\hline S2 & 0 & 56 & 2 & $\mathbf{2}$ & 1 & 0 & $\mathbf{1}$ & 0 \\
\hline BARIS BARU & 0 & 20 & 0 & 0 & 1.5 & 0 & -0.5 & 1 \\
\hline
\end{tabular}

Tabel 9. Iterasi Kedua

\begin{tabular}{|c|c|c|c|c|c|c|c|c|}
\hline \multirow{2}{*}{$\begin{array}{l}\text { VARIABEL } \\
\text { DASAR }\end{array}$} & \multirow{2}{*}{ TUJUAN } & $\mathbf{C j}$ & \multirow{2}{*}{$\frac{2,492.00}{\mathbf{X}}$} & \multirow{2}{*}{$\begin{array}{c}3,767.40 \\
\mathbf{Y} \\
\end{array}$} & \multirow{2}{*}{$\begin{array}{c}2,200.80 \\
\mathbf{Z} \\
\end{array}$} & \multirow{2}{*}{$\begin{array}{c}0 \\
\text { S1 } \\
\end{array}$} & \multirow{2}{*}{$\begin{array}{c}0 \\
\mathbf{S 2} \\
\end{array}$} & \multirow{2}{*}{$\begin{array}{c}0 \\
\mathbf{S 3} \\
\end{array}$} \\
\hline & & \begin{tabular}{l|l}
$\mathbf{K}$ & $\mathbf{Q}$ \\
\end{tabular} & & & & & & \\
\hline $\mathrm{S} 1$ & 0 & 104 & 3 & 2 & 2 & 1 & 0 & 0 \\
\hline $\mathbf{Y}$ & 3767.40 & 28 & 1 & 1 & 0.5 & 0 & 0.5 & 0 \\
\hline $\mathbf{Z}$ & 2200.80 & 20 & 0 & 0 & 1.5 & 0 & -0.5 & 1 \\
\hline \multicolumn{2}{|c|}{$Z_{j}$} & 149503.20 & 3767.40 & 3767.40 & 5184.90 & 0 & 783.30 & 2200.80 \\
\hline \multicolumn{3}{|c|}{$\mathbf{C j}-\mathbf{Z j}$} & -1275.40 & 0.00 & -2984.10 & 0 & -783.30 & -2200.8 \\
\hline
\end{tabular}


F. BARIS BARU selain BARIS KUNCI = BARIS LAMA - (RASIO KUNCI x BARIS KUNCI LAMA)

\begin{tabular}{|c|c|c|c|c|c|c|c|c|}
\hline \multicolumn{9}{|c|}{$\mathrm{RK}=2 / 2=1$} \\
\hline S1 & 0 & 104 & 3 & 2 & 2 & 1 & 0 & 0 \\
\hline S3 & 0 & 48 & 1 & 1 & 2 & 0 & 0 & 1 \\
\hline BARIS BARU & 0 & 56 & 2 & 1 & 0 & 1 & 0 & -1 \\
\hline
\end{tabular}

Tabel 10. Iterasi Ketiga

\begin{tabular}{|c|c|c|c|c|c|c|c|c|c|}
\hline \multirow{2}{*}{$\begin{array}{c}\text { VARIABEL } \\
\text { DASAR }\end{array}$} & \multirow{2}{*}{ TUJUAN } & \multicolumn{2}{|c|}{$\mathbf{C j}$} & \multirow{2}{*}{$\frac{2,492.00}{\mathbf{X}}$} & \multirow{2}{*}{$\frac{3,767.40}{\mathbf{Y}}$} & \multirow{2}{*}{$\frac{2,200.80}{\mathbf{Z}}$} & \multirow{2}{*}{$\begin{array}{c}0 \\
\text { S1 }\end{array}$} & \multirow{2}{*}{$\begin{array}{c}0 \\
\mathbf{S 2}\end{array}$} & \multirow{2}{*}{$\begin{array}{c}0 \\
\mathbf{S 3}\end{array}$} \\
\hline & & $\mathbf{K}$ & $\mathbf{Q}$ & & & & & & \\
\hline S1 & 0 & \multicolumn{2}{|c|}{56} & 2 & 1 & 0 & 1 & 0 & -1 \\
\hline $\mathbf{Y}$ & 3767.40 & \multicolumn{2}{|c|}{28} & 1 & 1 & 0.5 & 0 & 0.50 & 0.2 \\
\hline $\mathbf{Z}$ & 2200.80 & \multicolumn{2}{|c|}{13} & 0 & 0 & 1 & 0 & -0.33 & 0.67 \\
\hline \multicolumn{2}{|l|}{$\mathbf{Z j}$} & \multicolumn{2}{|c|}{134831.20} & 3767.40 & 3767.40 & 4084.50 & 0 & 1150.10 & 2220.68 \\
\hline \multicolumn{4}{|c|}{$\mathbf{C j}-\mathbf{Z j}$} & -1275.40 & 0.00 & -1883.70 & 0.00 & -1150.10 & -2220.68 \\
\hline
\end{tabular}

Tabel 11. Iterasi Keempat

\begin{tabular}{|c|c|c|c|c|c|c|c|c|c|}
\hline \multirow{2}{*}{$\begin{array}{l}\text { VARIABEL } \\
\text { DASAR }\end{array}$} & \multirow{2}{*}{ TUJUAN } & \multicolumn{2}{|c|}{$\mathbf{C j}$} & \multirow{2}{*}{$\frac{2,492.00}{\mathbf{X}}$} & \multirow{2}{*}{$\frac{3,767.40}{\mathbf{Y}}$} & \multirow{2}{*}{$\frac{2,200.80}{\mathbf{Z}}$} & \multirow{2}{*}{$\begin{array}{c}0 \\
\text { S1 }\end{array}$} & \multirow{2}{*}{$\begin{array}{c}0 \\
\mathbf{S 2}\end{array}$} & \multirow{2}{*}{$\begin{array}{c}0 \\
\mathbf{S 3}\end{array}$} \\
\hline & & $\mathbf{K}$ & $\mathbf{Q}$ & & & & & & \\
\hline $\mathbf{X}$ & 2.492 .00 & \multicolumn{2}{|c|}{28} & 1 & 0.5 & 0 & 0.5 & 0 & -0.5 \\
\hline $\mathbf{Y}$ & 3.767 .40 & \multicolumn{2}{|c|}{28} & 1 & 1 & 0.5 & 0 & 0.50 & 0.2 \\
\hline $\mathbf{Z}$ & 2.200 .80 & \multicolumn{2}{|c|}{13} & 0 & 0 & 1 & 0 & -0.33 & 0.67 \\
\hline \multicolumn{2}{|l|}{$\mathbf{Z j}_{\mathbf{j}}$} & \multicolumn{2}{|c|}{204.607 .20} & 6.259 .40 & 5.013 .40 & 4.084 .50 & 1.246 & 1.150 .10 & 974.68 \\
\hline \multicolumn{4}{|c|}{$\mathbf{C} \mathbf{j}-\mathbf{Z j}$} & -3.767 .40 & -1.246 .00 & -1.883 .70 & -1.246 .00 & -1.150 .10 & -974.68 \\
\hline
\end{tabular}

Dari proses perhitungan di atas (Tabel Iterasi Keempat), sudah tidak ada lagi nilai $\mathrm{Cj}-\mathrm{Zj}$ yang positif dan hal ini menunjukkan pemecahan masalah LP-Simpleks sudah optimal. Karena sudah optimal maka studi kasus perancangan boneka pada usaha kecil ini dapat dibuat dengan rancangan produk sebagai berikut; untuk produksi Bantal Leher (X) adalah 28 buah, dan produksi untuk Bantal Sandaran Mobil (Y) adalah 28 buah, serta produksi Bantal Bulat (Z) adalah 13 buah. Dengan demikian Profit yang diharapkan dari ketiga varian produk boneka tersebut dapat diterima kurang lebihnya adalah Rp. 204.607.200,- dalam satu bulannya. Asumsi yang digunakan dalam mendukung hal ini mengacu pada variabel pendapatan dari hasil usaha boneka terpenuhi, jam kerja terpasang dalam satuan 8 jam per-hari, serta batasan kemampuan produksi pengusaha kecil dalam kapasitas order yang mengacu terhadap mesin produksi yang dimilikinya serta tenaga kerja yang terbatas dalam sistem upah-biaya yang diterapkannya.

Untuk model perancangan produk boneka yang diterapkan oleh pihak usaha kecil tersebut, peneliti mempunyai keyakinan bahwa upaya ini akan mampu meningkatkan kemandirian dalam bidang perekonomian yang berdaulat sehingga akan mampu membuka lapangan kerja baru dalam kontek pengembangan dan keberlanjutan usaha kecil bagi lingkungan terdekat utamanya dan secara wilayah kecamatan pada umumnya dengan tujuan agar mampu menjadikan salah satu penghasilan bagi masing-masing keluarga sehingga terpenuhi kebutuhan hidup secara berjenjang mulai dari kebutuhan sandang, pangan dan papan. Oleh karena itu perlunya sinergitas terhadap beberapa komponen yaitu bagi pengusaha kecil, pemerintah maupun dunia akademis. Hal ini akan mampu menciptakan iklim usaha di level mikro secara jangka pendeknya dan jangkauan panjangnya adalah keberlanjutan usaha yang digeluti oleh usaha kecil di bidang boneka yang terdapat di wilayah Bantargebang Kota Bekasi khususnya. 


\section{SIMPULAN}

Perancangan produk boneka pada unit usaha kecil dengan metode LP-Simplek menunjukkan bahwa kombinasi produksi pada tiga varian terdiri atas Produksi Bantal Leher (X) adalah 28 buah, produksi Bantal Sandaran Mobil (Y) adalah 28 buah, serta Produksi Bantal Bulat (Z) adalah 13 buah. Dengan kombinasi tersebut akan mampu memperoleh profit kurang lebih Rp. 204.607.200,00 dalam setiap bulannya. Artinya dengan menerapkan model LP-Simpleks pelaku usaha kecil memproduksi berdasarkan jumlah produk dengan memperhatikan total biaya dengan hasil yang optimal pada masing-masing variannya, sehingga ketika model ini dikembangkan maka akan mampu meningkatkan kemandirian ekonomi yang berdaulat bagi pelaku usaha kecil dan tenaga kerja, dan akan mampu menopang perekonomian masing-masing elemen yang menghasilkan kemandirian ekonomi yang berdaya saing. Produksi boneka mengacu order yang sesuai dengan keinginanan pelanggan terhadap varian yang dimiliki produsen usaha kecil. Kombinasi atau pasangan produk disesuaikan dengan profit yang optimal mengacu metode LP-Simpleks. Perlunya peningkatan pemahaman produk dan inovasi dengan berdasarkan desain harga, dan desain produk sendiri melalui pendidikan dan latihan atau workshop. Pentingnya pemahaman kemandirian perekonomian yang berdaulat terhadap pelaku usaha kecil dan tenaga kerja agar memberikan motivasi kerja secara mandiri dan berkesinambungan melalui model pendidikan dan latihan atau workshop. Pelaku usaha kecil lebih memanitance kepada tenaga kerja, pelanggan dan jika diperlukan lebih lanjut adalah pemodal atau investor.

\section{DAFTAR PUSTAKA}

[1] Undang Undang No. 9 (1995): USAHA KECIL, Presiden Republik Indonesia No: 9 Tahun 1995 (9/1995) Tanggal: 26 Desember 1995, Jakarta, Sumber: LN 74; TLN 3611.

[2] Pradita, Danang, Ivandi. Pencapaian Keberhasilan Usaha Melalui Inovasi Produks dan Kreatifitas (Survei Pada Sentra Boneka di Kopo Sayati Bandung. Jurnal Jbptunikompp-37314-9.

[3] Sriwidadi, Teguh. Agustina Erni (2013). Analisa Optimalisasi Produksi Dengan Linier Programing Melalui Metode Simpleks, Bunis University. Jakarta. Binus Bussines Review Vol. 4 No. 2 Nov. 2013.

[4] Undang-undang Republik Indonesia N0. 20 (2008): Usaha Mikro, Kecil, dan Menengah.

[5] Ocktilia H. (2004). Pemberdayaan Ekonomi Rakyat Melalui Penguatan Kemitraan Lokal (Kasus pada pengrajin boneka kain di kelurahan Sukagalih Kecamatan Sukajadi Kota Bandung). Thesis. Bogor (ID): Institut Pertanian Bogor.

[6] Taha, Hamdy A. (1996). Riset Operasi Suatu Pengantar. Jilid I, Binarupa Aksara, Jakarta.

[7] Hiller, Frederick S And Liberman, Gerald J. (1990). Introduction To Operation Research. Mc Graw-Hill, Inc.

[8] Aminuddin, (2005). Prinsip-prinsip Riset Operasi, Erlangga, Jakarta. 